\title{
Correspondence
}

\section{Curb anchor scour for green shipping}

In charting a course for the greening of the shipping industry (Z. Wang et al. Nature 530, 275-277; 2016), we should also mitigate the scouring of seafloor biota by the massive anchors and long dragging chains dropped by a global fleet of some 68,000 ocean-going commercial vessels.

Cruise liners, too, are proliferating, with many approaching the size of supertankers. Anchoring in exotic, near-pristine locations potentially causes greater seafloor damage than it does near longused commercial ports, which may already have been stripped by behemoths deploying anchors weighing in excess of 30 tonnes.

Ships swinging at anchor destroy seafloor animal 'forests', as well as the resources and ecosystem services they support (S. Rossi Ocean Coast. Mgmt 84, 77-85; 2013). Yet the shipping industry's environmental code of practice does not recognize anchoring as a cause of concern (International Chamber of Shipping Shipping and the Environment: A Code of Practice, 2008).

As seaborne trade grows apace (pictured), there is an urgent need to assess the risks it poses to marine biodiversity. A solution could be to define safe anchorages near ports that reduce ships' physical footprints and avoid areas of high conservation value.

Andrew R. Davis, Allison Broad University of Wollongong, Australia.

adavis@uow.edu.au

\section{Renewables targeted before Fukushima}

Masahiro Sugiyama and colleagues write that Japan expanded the role of renewables after the 2011 Fukushima Daiichi nuclear accident (Nature 531, 29-31; 2016). In fact, Japan's targets for renewables

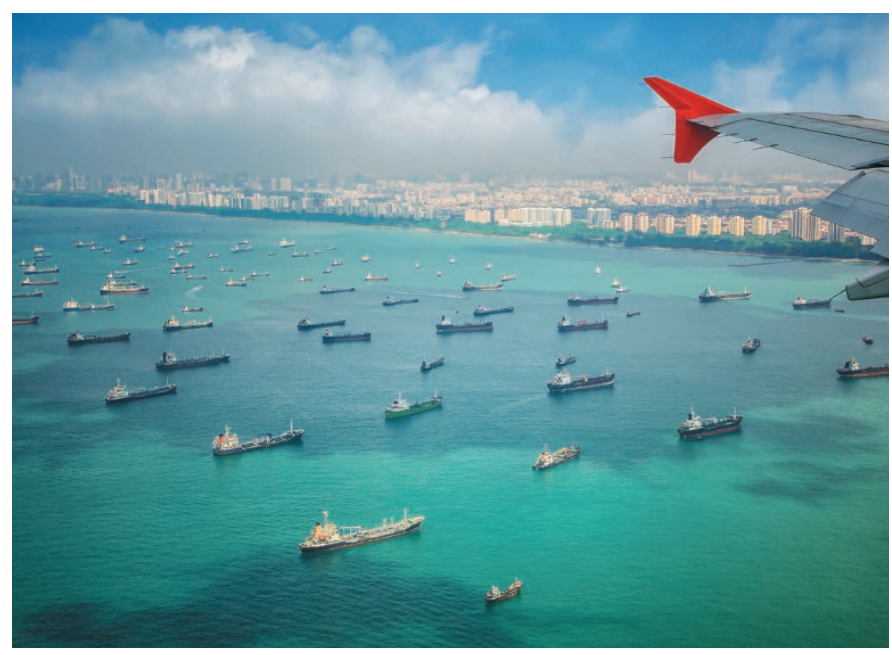

Cargo ships off Singapore, one of the world's busiest ports.

were essentially unaffected by the disaster - although the country did alter its nuclear plans.

Japan's projected electricity mix for 2030 is set out in its Strategic Energy Plans. The 2014 plan (see go.nature.com/ xnkn4k) aims to cut nuclear power's contribution to $20-22 \%$ by 2030 , down from $53 \%$ in the 2010 plan (J. Duffield and B. Woodall Energy Policy 39, 3741-3749; 2011). Fossil fuels, not renewables, are set to make up the shortfall - with the projected contribution for 2030 up by $30 \%$ compared with the 2010 plan. Meanwhile, the 2014 plan's 23\% contribution from renewables by 2030 is almost unchanged (21\% in the 2010 plan).

The authors rightly praise Japan's post-Fukushima attempt to expand solar power. For several decades, the country has developed this technology alongside nuclear power (R. Bointner Energy Policy 73, 733-747; 2014). Japanese companies such as Sharp, Sanyo and Kyocera pioneered solar energy, whereas Hitachi, Mitsubishi and Toshiba became leaders in nuclear power. It is good news for the global climate that these technologies can be developed alongside each other. Aleh Cherp Central European University, Budapest, Hungary.
Jessica Jewell International Institute for Applied Systems Analysis, Laxenburg, Austria. cherpa@ceu.edu

\section{Debate over whale longevity is futile}

The unquestionable importance of ethical animal husbandry aside, I doubt whether the ongoing dispute over the respective lifespans of captive and wild killer whales (Orcinus orca) will contribute anything to our long-term efforts to save the species (see Nature 531, 426-427; 2016).

The days of keeping killer whales in captivity are in any case numbered for marine parks such as SeaWorld in the United States. And the conservation value of breeding the tiny number of captive killer whales worldwide is negligible.

In my view, we should be focusing on the real conservation plight of wild killer-whale populations around the globe (see, for example, R. Esteban et al. Ecol. Indic. 66, 291-300; 2016). In the main, these are so poorly understood that entire populations are at risk of extinction (see P. J. N. de Bruyn et al. Biol. Rev. 88, 62-80; 2013).

Meanwhile, we waste precious resources debating the longevity of a handful of captive animals.

P. J. Nico de Bruyn University of Pretoria, South Africa. pjndebruyn@zoology.up.ac.za

\section{Shared goals score reproducible results}

As every manager knows, the goals of the employee and the organization must be aligned for success (A. Edwards Nature 531, 299-301; 2016). In my experience of industry and academic research, there is no such driver in academia.

Academics' goals are to confirm that their ideas are correct, to publish quickly and to solicit extra grant money, whereas the goal of their funding agencies is to better society. Industry and its employees have a common goal - to develop a saleable product.

This alignment means that there is little individual incentive in industry to fabricate data: drugs developed from flawed preclinical results, for example, are doomed to fail expensive multi-centre clinical trials. Irreproducibility in academic research is all too common (see Nature 515, 7; 2014); in industry it is a sackable offence.

There is still some stigma attached to academics with close ties to industry, but funding agencies would do well to take note of these individuals. People in industry are not interested in working with those whose results are not reproducible.

Eric Buenz Nelson Marlborough Institute of Technology, Nelson, New Zealand. eric.buenz@nmit.ac.nz

CONTRIBUTIONS

Correspondence may be submitted to correspondence@nature. com after consulting the guidelines at http:// go.nature.com/cmchno. 